\title{
Moral Reciprocity, Ethics of Appropriation of Indigenous Medicinal Plant Knowledge and Associated Biopiracy
}

\section{Oscar Agbor Ambang - Sergio Alloggio - Roman Tandlich*}

Received: March 8, 2019; received in revised form: May 31, 2019; accepted: June 3, 2019

\begin{abstract}
:
Introduction: Although this paper deals mostly with the positive effects of a posthumanist worldview on environmental sustainability, partnership, or moral accountability in science and scientific research, it also promotes a new understanding of our educational practice in higher education. The ideas espoused have the ability to inspire educators at all levels to show students, future researchers or other professions about the importance of a progressive, holistic approach to our environment. We claim that being sensitive and caring for our environment is not only part of our moral and ethical responsibility, it is an inseparable aspect of our environmental education, our environmental intelligence. This paper discusses posthumanist ${ }^{1}$ reciprocity ethics in the context of traditional knowledge (TK) and the protection of indigenous traditional knowledge from commercial exploitation.

Methods: Instances of unethical bioprospecting and biopiracy were common throughout the turn of the 21 st century and are discussed using cases in countries such as Cameroon, India, South Africa and Australia, where medicinal plant species were, are still a highly sought-after source of potent, pharmacologically active phytochemicals.

Results and discussion: The observed increase in regulations against bioprospecting on indigenous land in these countries as a result of intellectual property monopoly by big pharmaceutical companies is discussed in this paper along the lines of a 'humanist vs posthumanist' ontology. Patent exclusivity laws have historically marginalized the proprietary owners of indigenous traditional knowledge, creating a moral
\end{abstract}

\footnotetext{
* Oscar Agbor Ambang, Rhodes University, Faculty of Pharmacy, Grahamstown, South Africa; g13a5774@campus.ru.ac.za

Sergio Alloggio, Independent Researcher, South Africa; s_alloggio@ hotmail.com

Roman Tandlich, Rhodes University, Faculty of Pharmacy, Grahamstown, South Africa; r.tandlich@ru.ac.za

${ }^{1}$ Posthumanism is a new approach in contemporary philosophy that deconstructs some of the most fundamental assumptions of modern Western culture, its ontology, epistemology and ethics. It is a critical approach that aims at understanding the role of the human subject in relation to both the natural world and knowledge-production practice, and how that relationship plays out into socio-cultural and socio-political spheres of society.
} 


\section{Acta Educationis Generalis \\ volume 9, 2019, issue 2}

and ethical rift between those that seek to exploit this knowledge commercially and those from whom the knowledge originally comes from. This disconnection from nature and natural resources due to a humanistic approach $^{2}$ to growth and development, often leads to environmental exploitation, exploitation of indigenous people and unsustainable commercial practices. Existing research and bioprospecting ethics that are practiced on indigenous lands must be questioned in their ability to provide mutually beneficial outcomes for all stakeholders.

Conclusions: The posthumanist approach to morality and research ethics is discussed in this paper as a possible and practical alternative to humanism along with the potential for posthumanist ethics to be a tool to shape legal frameworks and the policies that protect at-risk communities and their respective natural environments. Our current developmental trajectory as a collective species has us blurring the lines that separate the 'human' from the 'non-human' elements in our world as humanity grows towards a more technologically advanced but equally environmentally dependent people. Thus, the currently existing systems of ethics that govern the relationship between the 'human' and 'non-human' must be called into question. This paper aims to illustrate the positive effects of a posthumanist worldview on issues such as environmental sustainability, partnership, moral accountability and reciprocity ethics in the context of modern science and modern scientific research.

Key words: moral reciprocity, ethics, biopiracy.

\section{Introduction}

Morals and ethics are two words that are often used synonymously yet refer to slightly different facets of distinguishing "right" from "wrong." Most people think of morals as a personal or normative perception while ethics encompass a more broadly applicable set of ideals that are to a degree enforced in certain shared spaces. Ethical codes that are followed in these shared spaces require the establishment of a governing body that provides oversight and regulation and can keep members of said space accountable to one another (Nortjé \& Hoffmann, 2015). Ultimately, perceptions are really what distinguish morals from ethics. A good example is the perceptions surrounding polygamy. A community may consider polygamy immoral (as in a matter relating to morality) and individuals may agree with the notion or polygamy may not be a matter strongly contested in a community (as far as communal ethics are concerned), yet an individual or individuals might consider it immoral (Encyclopedia

\footnotetext{
${ }^{2}$ Humanism is here understood as a philosophical school of thought that advocates progressive and critical thinking but tolerates no epistemic space for extrahuman beliefs: the human (cap)ability is the only candidate to lead an ethical life. However, humanistic approaches place human beings at the centre of every research practice, thus discriminating against non-human entities in nature like animals and natural resources.
} 


\section{Acta Educationis Generalis \\ volume 9, 2019, issue 2}

Britannica, 2018). As such the distinction in this case matters and the question becomes a matter of the subject being discussed i.e., the community or the individual. In the latter instance, the individual's morality is in contradiction of the ethics of the community, so the subject of polygamy becomes a question of "who's ethics?" This ethical conflict is a complex one where the individual may feel compelled to have certain stances on certain issues due to personal convictions and wish to follow their own moral compass despite the larger community having already established ethico-political norms and values that pressure individuals to conforming and also shape its legal atmosphere and that of the individuals in it (Alexander \& Moore, 2016).

This argument has long been the topic of philosophical debate in an argument that fundamentally can be reduced down to a debate of normative ethics-a field of philosophy concerned with the study of ethics relating to an individual's duty to a larger community versus their free will and independent agency. It is an ageold philosophical dilemma best described as a Deontological versus Consequentialist (Utilitarian) conflict. Consequentialism is the ethical stance which determines whether an action is good or bad solely based on the consequential effects said action has on the world (Alexander \& Moore, 2016). As such, the greatest good is achieved via actions that have a net positive effect on the world or by those actions which bring about the "Greatest Happiness". The "Greatest Happiness Principle", put forward by British philosopher John Stuart Mill, is a moral view based on the idea of utility. This moral view holds the position that happiness is the benchmark for establishing what is moral or immoral irrespective of the motivations of the actions or how happiness is achieved; in other words, the ends justify the means. Utilitarianism is the most commonly practiced and the most elementary form of consequentialism due to its binary approach to moral problems. Utilitarianism not only claims that the only desirable and valued consequence of any action is happiness but also that the only undesirable or disvalued consequence of an action is pain (Nahra, 2014).

Deontological ethics is seen as the antithesis to consequential ethics in that deontology concerns itself with the nature of an action and not simply the outcome (Korsgaard, 2004). Made famous by German philosopher Immanuel Kant, deontological principles are rooted in the assumption that moral judgement is contained in the action alone and the consequences do not hold any significance (Mandal, Ponnambath, \& Parija, 2016). Kant proposed two main 'absolute' moral laws or 'maxims' known as the 'categorical imperatives' which are based on the idea that morality is ultimately derived from rationality and all moral judgements have rational foundations that apply objectively to every individual. Kant's first maxim states "Act only on maxims that you can simultaneously will to become a universal law." This means that the true meaning of moral positions are not based on particular, contingent conditions including the identity of the particular individual making said decisions 


\section{Acta Educationis Generalis \\ volume 9, 2019, issue 2}

(Alexander \& Moore, 2016). For example, if one were to perform a certain bad action and it became such that everyone else did the same action, for the same reasons, then it is not morally justifiable for the individual to desire 'special treatment' or be upset by notion that others would do the same. This maxim specifies that all actions must have universality as their general premise i.e., one should only perform an action if they are content with every other individual on Earth doing the same action all the time (Korsgaard, 2004).

The second maxim is a direct contradiction to utilitarian ethics in that it recognizes human beings as an end rather than a means to an end (Three Minute Philosophy: Immanuel Kant, 2009). It states "Act so that you treat humanity, whether in your own person or in that of another, always as an end and never as a mere means" (Alexander \& Moore, 2016). This means that the manipulation of individuals to achieve an end or achieving a goal at the expense of another individual is morally bad and violates the universal dignity of every human being. It is absolute in the sense that it is not conditional to any contingent aspect of life and applies to the most basic scenarios or situations, for example, lying (for any reason or under any circumstances) is immoral according to Kantian deontology (Three Minute Philosophy: Immanuel Kant, 2009).

Similarly, clinical practice often requires guiding from medical normative ethics and it is largely concerned with the deontological versus consequentialist philosophy in as far as how the obligations, duties and decisions of medical professionals may affect potential patient outcomes and considers all of the associated consequences of said decisions (Mandal, Ponnambath, \& Parija, 2016). It has long been argued that the bedrock of biomedical ethics is grounded in its four critical principles, namely autonomy, beneficence, nonmaleficence and justice - an approach to medical practice known as Principlism (Gillon, 1994). Popularized by medical ethicist Raanan Gillon in the 1970s, these principles form common themes in the ethical guidelines of many health care professions around the world and also, in South Africa (Ramdas, 2017; World Medical Association, 2019). However, in clinical practice, the implementation of these principles is challenging because of the glaring inconsistencies that it presents in cross-cultural contexts (Azétsop \& Rennie, 2010).

\section{Principlism and principle oriented medical ethics}

\subsection{Non-maleficence}

Non-maleficence operates on the dictum "First do no harm", a notion which is seemingly obvious in a profession that is dedicated to ameliorating illness, but the complications arise when one has to consider what philosophical doctrine to adopt when defining the word "harm". A consequentialist approach would see harm as that which prevents good from occurring or that which leads to less good while on the other hand a deontological ethical view would be to view 


\section{Acta Educationis Generalis \\ volume 9, 2019, issue 2}

harm as those actions which prevents one from carrying out one's duty. In clinical settings, the controversy as to what constitutes harm can vary depending on moral stances. Since much of healthcare involves pain, discomfort, disfigurement or even disability in the case of amputation or skin graft, for example, harm becomes less absolute and more so a circumstantial event. Does the treatment for a severely infected limb justify the disfigurement and disability one would experience from amputation? Do the ends justify the means? Taking a consequentialist ethical stance, the greatest utility/greatest good would come from accepting the dismemberment as part of the cost of a greater treatment (Morrison \& Furlong, 2009).

\subsection{Autonomy}

The idea of autonomy is deeply significant in medical practice and associated medical ethics. Autonomy involves total sovereignty when it comes to choices and decisions. Autonomy in a medical context can be explored using Kant's second maxim; the notion that suggests one must treat people as ends and not just means to an end. The idea of autonomy becomes a matter of controversial debate when one considers the effects of an individual autonomous medical/health decisions on the greater community. An example of this would be the choice to vaccinate oneself/one's children. According to Le Blanc (2009), in instances where an individual believes that vaccination/immunization is a violation of their religious/spiritual beliefs (or for any other reason), they resort, by default, to relying on herd immunity to prevent the occurrence of an outbreak. It's worth mentioning that many of the beneficiaries of herd immunity are not necessarily opposed to the idea of being vaccinated but are unable to do so due to circumstances such as pregnancy or immunocompromisation. Addressing the issue of herd immunity on Kantian ethical lines shows us that "Anti-vaxxers"- a term used to describe persons who are opposed to vaccination- are in violation of the second Kantian maxim because they are using the community as a "pseudovaccine" without its prior consent or approval. In essence, the community is non-consentingly being used as a means to an end and not being recognized as an end itself; a direct impingement to Kant's categorical imperatives. Kantian deontology greatly emphasizes moral duty over the consequences of actions, which in the context of immunization, can be interpreted as a moral duty of every individual to ensure their own immunization and that of those closest to them (Le Blanc, 2009). According to a utilitarian ontology, the consequences of non-immunization are an increased risk of an outbreak and a heavy dependence on those who are vaccinated to provide protection (Nahra, 2014). This does not serve the greater good of the community but only the perceived good of the individual and according to Kantian consequentialism, this is morally bad (Nahra, 2014). The opposite is true for those individuals who ascribe to vaccination because they acknowledge the personal benefit of immunization as 


\section{Acta Educationis Generalis \\ volume 9, 2019, issue 2}

well as the greater effect it has on the community in provide herd immunity (Le Blanc, 2009).

\subsection{Beneficence}

According to Beauchamp's (2016) definition, beneficence is any altruistic action that connotes a merciful deed, act of kindness or philanthropy such as charitable donations to medical research, scholarships for community education and animal welfare, to name a few. The principles of beneficence can be traced to a moral obligation to act in the best interests of others and aiding them in their pursuit of their own fulfillment and self-actualization. From a utilitarian ethical stance, which ascribes to the Greatest Happiness Principle is a fundamental requisite for morality, an action is morally just if it leads to the maximum beneficial outcome or to the least possible adverse outcome. That is to say beneficence is fundamental to the moral satisfaction of this ethical doctrine. Utilitarianism holds other values such as duty, obligation or rights as subordinate to those actions which maximize benefit or minimize harmful outcomes. Utility, as discussed by many utilitarians, is an absolute principle which means beneficence, in this context, is understood as the only ethical principle of significance because it focuses on the provision of maximum benefit (Beauchamp, 2016).

From a Kantian deontological perspective, beneficence has a place in ethical conversations only if the motives behind the action are not driven by sentiment but by a sense of duty. Kantian ethics argues that beneficence is a moral obligation applicable to all persons and that individuals must do so in a manner that is in accordance with their capacity to be benevolent all the while being void of the expectation of recompense. The ideology of providing benefit to an individual out of a sense of duty is a central concept to the nature of medicinal practice and is intrinsic to the moral conviction of the modern professional physician. It is argued that if medicine is about providing healing then professional healthcare services are fundamentally a beneficent undertaking and have no other purpose outside of ameliorating illnesses. This is however not always the case when one considers a situation where a medical procedure is not necessarily life threatening nor focused on healing per say, but still to the benefit of a patient. For example, when surgeons perform cosmetic/aesthetic surgery (as opposed to reconstructive surgery), or an endocrinologist providing fertility therapy or even in the instance of assisted death requested by a patient with a terminal diagnosis; these medical interventions are still in the interest of the patient and provide them with a 'benefit' subjective to their particular desires and wills (Beauchamp, 2016). The question then is- if it is the duty of a healthcare professional to comply with a patient's request for accelerated death for example, are they acting in a beneficent manner despite death being a natural opposite to health/healing, which is fundamental to beneficent medical therapy? The discussion is thus a matter of what counts as a 'medical practice' and what 


\section{Acta Educationis Generalis \\ volume 9, 2019, issue 2}

constitutes medical beneficence: Where is the line between beneficence and paternalism?

\subsection{Justice}

The issues of justice were dealt with by Azétsop and Rennie (2010) They define justice as a critical concept when discussing the implications of various virtue ethics in clinical and research settings. Contemporary ideas of biomedical justice rely on the concept of autonomy-centred healthcare which primarily focuses on patient rights, rules of informed consent and rules of refusal and patient confidentiality as part of a field of medical philosophy known as autonomybased bioethics. The criticism of this largely adopted ethical stance is that it is incapable holding consistency in economically poor countries where health and health accessibility are closely connected to socio-economic position and access to resources. The agency and autonomy that is core to contemporary biomedical ethics is deeply related to the commoditization of medicine and commercialization of healthcare especially in developed countries. This trend has changed the patient-physician relationship to one that is more akin to a client-service provider relationship in that it has become less paternal and more respectful/acknowledging of the affluence and power at the disposal of many patients who can afford to pay for the services. Access to resources, literacy and health education contribute greatly to the effect of a patient's autonomy in clinical scenarios in that they are able to rationally weigh their treatment options, which may agree or disagree with the advice of the healthcare professional and also be in a position to pay for the services they require (Azétsop \& Rennie, 2010).

In economically poor countries, community members face different challenges when seeking healthcare services largely due to financial constraints. Going to see a physician places a large financial burden on members of a family who earn an income especially if the patient is a source of income for the family. The expectation is for the patient to receive mediation or a medical procedure so they can return to work to provide for dependents because time spent in hospital or in recovery at home translates to no work and thus impinges the income of the family. These patients struggle to afford the adequate nutrition and dietary supplementation necessary for proper recovery among all the other medical challenges their circumstances present them and are, thus, not in a position to demand the same healthcare services and express the same autonomy at the disposal members of more socioeconomically affluent countries and communities (Azétsop \& Rennie, 2010).

Therefore, there are limitations to the normative biomedical ethics surrounding autonomy in that they cater more towards the autonomy of the patient and often take advantage of this autonomy in the forms practice that insulate professionals from accusation, malpractice and legal repercussion (a barrier to patient justice itself). The ethical paradigm should then adopt a broader, more inclusive 


\section{Acta Educationis Generalis \\ volume 9, 2019, issue 2}

understanding of the determinants of health and wellbeing especially those that involve socioeconomic inequality and access to resources in order to formulate and dispense comprehensive and informed judicial decisions (Azétsop \& Rennie, 2010).

\subsection{Normative ethics in professional healthcare}

Many countries have ethical guidelines that regulate professional conduct in the healthcare sector and these councils often do so by reference to ethical guidelines that umbrella all those who fall under their prescribed health professions (Fanzo, 2015). South Africa has the Health Professions Council of South Africa (HPCSA) which, in its description of their guiding principles cites the necessity for both an ethical approach to treating patients, "[...sound commitment to ethical practices...]" and also a good moral compass "[...the practice of healthcare is a moral enterprise]" (Hpcsa.co.za, 2016). So both morals and ethics play integral roles in delivering the best possible treatment to those in need and are there to guide health practitioners through difficult real-life instances of moral and ethical dilemma which are commonplace in healthcare systems. Many healthcare guidelines have Gillon's four ethical principles as common parameters for good ethical conduct and have additional principles which in some way hold the wellbeing of the patient in highest regard and cater towards patient protection and ethical treatment. The HPCSA stipulates 13 core ethical values that all professionals must cater to, all of which stem from universally desirable moral values. Revered values such as compassions, respect for persons, value of life and self-reflection are common themes observed in these guidelines (Hpcsa.co.za, 2016). These values in some way or other correlate to a positive patient outcome:

1. Respect for persons: Every individual has the common desire to be treated with dignity and respect. The value of life and desired individual health is common ground for both the patient and health practitioner and thus in the clinical setting both parties should show mutual respect for one another.

2. Non-maleficence: The health practitioner should have the patients' best interest at heart to carry out the best course of treatment for their ailment. The intent to harm (maleficence) could directly relate to negative and undesirable patient outcomes.

3. Beneficence: The idea on beneficence is a posthumanist one that values the experiences and interest of the patient above that of the self (the caregiver). The healthcare practitioner must set aside their own personal biases and sentiments which may conflict with that of the patient.

4. Human rights: The practitioner should acknowledge the basic human right to health, freedom of choice, freedom to express opinion and other rights that are fundamental to the human dignity. 


\section{Acta Educationis Generalis \\ volume 9, 2019, issue 2}

5. Autonomy: This value, similar to human rights, involves the health practitioner recognizing and honoring the desires of the patient to selfdetermination and to live their lives by their own values and beliefs.

6. Integrity: Integrity of the patient should be upheld throughout their interaction with their caregiver. Their dignity must not be compromised as result of a desired outcome.

7. Truthfulness: The health practitioner must be transparent and sincere in their approach to caregiving. The best course of action to treat a patient can only be carried out once all the facts have been truthfully and accurately presented.

8. Confidentiality: confidential patient information must be kept private in patient -caregiver relationships unless legally or in some cases morally obligated to disclose said information.

9. Compassion: Health practitioners should be sensitive to patient conditions and should aim to develop empathy for ailment. This compassion could lead to a greater appreciation for life and a better approach to delivering healthcare. This approach will lead to better patient outcomes.

10. Tolerance: The rights of patients who may have different ethical beliefs to those of the health practitioner must be recognized and respected regardless of moral, cultural or religious convictions.

11. Justice: The impartial and just treatment of all patients with equal attention and just resource allocation should be the approach to caregiving.

12. Professional competence and self-development: Healthcare practitioners should seek to improve their skills and knowledge based on the growing global pool of medical information.

13. Community: Health practitioners should strive to make contributions to society by channeling their professional skills to tackle the issues communities face at basic levels. Information regarding personal and communal hygiene, water management, information about maternal/infant nutrition to name a few, can be provided to the community by health care practitioners who are equipped in their respective fields (Hpcsa.co.za, 2016).

In addition to this, specific healthcare professions will commonly have a board that regulate the specific conduct and responsibilities of various levels of personnel in that particular field of healthcare such as clinical nutrition (Hpcsa.co.za, 2018). For example, dietitians in South Africa are governed by the Professional Board for Dietetics which provides general rules and regulation for all practitioners and also specifies the scopes of practice of various specialists in the field (Professional Board of Dietetics, 2006). Similarly, the pharmacy profession has the South African Pharmacy Council (SAPC) as the selfregulating administrative body of the profession with its own specifications and scopes of practice for various levels of pharmacy professional 


\section{Acta Educationis Generalis \\ volume 9, 2019, issue 2}

(Pharmcouncil.co.za, 2011). These professionals are bound to a code of professional conduct which has the same core moral and ethical values as those set out by the HPCSA but also give provisions for the various legislation that are implicated in the pharmacy profession in the form of a compendium of laws. Also, seeing as how healthcare, ultimately, is a service to the general public (the customer), it is accountable to customer protections laws outlined in South African legislation (Pharmcouncil.co.za, 2011). The pharmacist code of conduct gives provisions for 12 principles in their code of conduct and each these codes of conduct are stipulated by the Pharmacy Act and they relate to one or more of the twelve ethical values outlines by the overarching HPCSA (South African Pharmacy Council, 2008):

i. Wellbeing of the patient: The intentions of the pharmacist must be to improve the condition of those under their care. The health, wellbeing, dignity and safety of the patient and general public must be paramount. Ethically this implies that the pharmacist must be beneficent, nonmaleficent, compassionate and just in their actions when carrying out professional responsibilities.

ii. Honour and dignity of the profession: A pharmacist must maintain a standard of behavior within and outside of the professional practice and avoid instances that may bring the profession into disrepute. A pharmacist must employ their professional competence and skill set to gain positive outcomes for the patient(s) and the greater community to which they belong/practice in. The ethical values of community and professional selfdevelopment are implicated in this code of conduct.

iii. Confidentiality: A pharmacist must never abuse the position of power over a patient but must respect a patient's rights, dignity, autonomy and entitlement to confidential information except under prescribed conditions.

iv. Continuing professional development (CPD): This relates to the ethical code of professional competence and self-development where selfawareness in professional situations or otherwise are encouraged. Pharmacist must keep abreast of the progress of knowledge development.

v. Cooperation with other health professionals: A pharmacist must cooperate with professionals of other field to explore better more catered options of treatment and to maximize the positive outcomes for a patient.

vi. Professional independence: A pharmacist must strictly observe and adhere to the guiding principles in the code of conduct and must not act or let anyone on their behalf, do anything which would constitute a breach of this code of conduct or impairs their ability to carry out their professional duties. The integrity for persons and that of the profession must be considered simultaneously. This includes accepting bribes, favorable treatment or giving partial treatment to specific patient in return for personal compensation, financial or otherwise. 


\section{Acta Educationis Generalis \\ volume 9, 2019, issue 2}

vii. Advertising: Pharmacies and their personnel should refrain from advertising with direct or indirect implications of superiority over other services provided by other pharmacies or pharmacists. Advertising must be dignified and must not bring the profession into disrepute.

viii. Professional appearance and nature of pharmacy: These principles relate to the professional and aesthetics of the pharmacy in that they comply with good pharmacy practice (GPP) standards which are a reflection of the professional character of the pharmacy as provided by the Pharmacy Act.

ix. Control over medicine: A pharmacist must execute proper control over all medicines and related substances which may be obtained from their pharmacy and must additionally be held accountable for misuse or abuse of medicines on the part of the pharmacist/pharmacy personnel.

$\mathrm{x}$. Chemical sold/provided in a pharmacy: Similar to the 'control of medicines' guideline, this stipulates that pharmacists must take measures to ensure that all chemical supplied from the pharmacy will be used for the proper intended purpose in the appropriate circumstances i.e. must exhibit control over all substances in the pharmacy.

xi. Dual registration: Registering with more than one statutory health council is allowed granted that the pharmacist complies with the ethical rules and codes of conduct of each of the respective registered professions they are affiliated to.

xii. Use of trading titles, brand names and logos: It is up to the pharmacist to ensure that all trading/advertising titles are in compliance with standards approved by the Pharmacy Council of South Africa (South African Pharmacy Council, 2008).

There is thus similarity in the core ethical principles in the various fields of medicine and healthcare that aim to serve as a guideline through challenging ethical conundrums. Gillon's Principlism is also observed to be a commonly used theme used to formulate biomedical ethical guidelines with various additional principles that give provisions for particularities of each profession. Normative ethics plays a role in the formulation of these ethical guidelines in that normative ethics stipulates what 'ought' to be done in morally conflicting situations that arise in clinical practice.

\section{Culture and societal ethics}

Human beings as a species are unique creatures in that we are the only species on the planet that does not interact with the world organically as far as experiencing reality goes i.e. unadulterated by perception. Microorganisms for example all interact with their environment in a manner that is simple and rudimentary. All interactions with the environment are natural and involve no alterations of perception to meet a desired means of experiencing their reality 


\section{Acta Educationis Generalis \\ volume 9, 2019, issue 2}

nor are they observed to do so in order to carry out biological functions that are necessary for their survival. Human beings on the other hand experience reality not only through organic/natural interaction with their environment but for the vast majority our interactions are guided by perceptions which are informed by culture (Draaisma, 2017). 'Culture' is an anthropological term that is used to encompass all the facets of the human experience that extends beyond physical/rudimentary interaction we have with our world. Culture is the evidence that humans are able to acknowledge themselves beyond the basic biological level in that culture is what bridges our biological/genetic nature to what we as humans require for nurture (McIntosh, 2018). The very fact that human beings observe and adhere to cultural phenomenon is evidence of an appreciation and acknowledgement for relationships between individuals within a culture (i.e the humans elements of a culture) and the non-human/ material elements of culture such as cultural symbolism, language, norms and morals (McIntosh, 2018). As mentioned previously, higher organisms such as human beings interact with their environment, in majority, by perception as opposed to the rudimentary biological interactions observed between microbiological life and their respective environments. For human beings, culture is the tool that shapes our perceptions of life, the environment and our perceptions of other individuals both inside and outside a particular culture and ultimately they inform how we experience reality (McIntosh, 2018). It must be however noted that the idea of 'culture' is not solely a human phenomenon as it can be argued that other animals such as lions for instance, possess a 'culture' that can be seen to include gender roles, hierarchy, elements of communal maternity etc (Burger, 2009). The difference with human being is that we are a single species that displays multiculturalisms across the globe, while it is argued that other animals such as lions have a monolith-like culture regardless of where they exist, in this sense lions are expected to be culturally identical everywhere (Laland \& Hoppitt, 2003; Burger, 2009).

As mentioned above with the example of polygamy, determining how it is perceived in a community, polygamy may or may not be deemed immoral, depending on the culture of the person(s) holding views on the matter (Nortjé \& Hoffmann, 2015). Thus, when dealing with matters that are of ethical and/or moral origin which, ultimately, translate to certain behaviors or biases, it must be kept in mind that human beings rely heavily on their preconceived notions of their society, preconceived notions that are a direct result of the social culture (Draaisma, 2017). This is evident in the way societies have been built across the world throughout history. For a society to function, all members must abide by minimum standards that are set out by overseeing/administrative bodies such as a set of laws that each member must be held accountable to (Knapp et al., 2007). The question of 'whose culture?' and 'whose ethics?' is pivotal when society forms its legal framework. Both laws and ethics provide guidelines that take into account the context for what is and what is not allowed in a certain 


\section{Acta Educationis Generalis \\ volume 9, 2019, issue 2}

society/setting (Visser \& Van Zyl IV, 2016). The ideals of laws provide the people a platform to benefit from being members of a regulated society (Knapp et al., 2007). The law tries to create an enforceable fundamental standard for a community to progress positively and have equal opportunities to do so while morals and ethics aim to improve a person at an individual level (Visser \& Van Zyl IV, 2016).

The difference between societal ethics and the legal framework is the jurisdiction of the administrative body to enforce these rules and regulations and the consequences associated with deviations from norms (Visser \& Van Zyl IV, 2016). Transgressing ethical standards of a society for the majority, does not have legal implications such as incarceration or a fine but can have an impact on the way society judges the individual's morality and can impose 'social sanctions' on said person(s) (Knapp et al., 2007). Going back to the example of polygamy, the practice of multiple partnerships is legal in South Africa under the Recognition of Customary Marriages Act (Act no. 120 of 1998) ('RCMA') where customs such as polygamous marriages are recognized as legal under the law. However, there may be individuals within South African society that hold a different worldview and have a varying stance to the law on the ethics of multiple partnerships and may thus deem it unethical. That said, South Africa is a democratic country that allows for a democratic plurality which encompasses all its diversity. Pluralism is the political philosophy that allows for power within a society to be distributed between its various social/cultural groups (Kozhikode \& $\mathrm{Li}, 2012$ ). This empowerment takes the form of equal rights, equal protections under the constitution, and strives for equal opportunity for all its constituents (Jahanbegloo \& Parekh, 2011). With such large cultural diversity in a population it is challenging to provide a set of legislation founded on a common fundamental set of morals and ethics that can apply to every sociocultural group in the country (Rosenberg, 2001). This makes identifying and addressing transgressions of the law difficult as certain practices in one cultural group may not be permissible in another and vice-versa.

In the example of polygamy, the custom is common among many members of several Islamic communities, the Zulu community, the Sotho community and many others in South Africa. Thus, the laws, and their intricate dissemination into daily life, cannot be adjudicated in the same manner as those cultures that do not subscribe to polygamous relationships (Rosenberg, 2001). South Africa resolves this conflict by implementing customary law which allow for multiple parties to enter a marriage (often two or more women to a man) (Musgrave, 2016). Former South African president Jacob Zuma is married to four women and King Mswati III of Swaziland who is married to 14 women are some examples of the plurality of morals and cultures that are accommodated within certain societies and also illustrates the degree of inclusivity of certain controversial customs such as polygamy into the social fabric of countries like South Africa (Musgrave, 2016). Thus, the way in which societal ethics and the 


\section{Acta Educationis Generalis \\ volume 9, 2019, issue 2}

legal framework interplay in a culturally plural society is very intricate and sensitive as the consideration for all members of all societies must be obligatory (Yumatle, 2016).

The RCMA was designed to protect women in a cultural setting that, for the vast majority, only benefits men. Dissecting the morals of polygamy uncovers a more subtle power imbalance between men and women with the scale being tipped in favor of men with the female member(s) of the polygamous group often being marginalized or exploited. In the same way, a company that benefits from traditional knowledge benefits from it individualistically, without the continued benefit being felt by the community. Therefore, community knowledge, which can be argued to be customary, must be considered for protection by similar customary laws to ensure their continued development and protection from commercial exploitation. It is arguable that the only way we ethically engage with communities is through a framework which ensures mutual ethical and mutually beneficial reciprocity practices.

Intellectual Property (IP) disputes dealing with TK are often, at their core, a matter of legitimacy. Both parties have the goal of achieving product exclusivity and a means to acknowledge said legitimacy through the legal framework (Wipo.int, 2006). The majority of the disputes between TK holders and those corporations that often exploit them is acknowledging and legitimizing where the source of the information came from (Wipo.int, 2006). Academic peer review is a research tool that scrutinizes a proposed piece of work by the peers of the author of a particular field and provides legitimacy to the information, methods of practice and sources of data that go into a publication (Voigt \& Hoogenboom, 2012). In this process, the data that is collected and put forward by the author on the subject matter is criticized based on its origin, authenticity, reliability of sources, reliability of the data analysis method(s), and accuracy in how it relates to the subject matter or hypothesized question (Voigt \& Hoogenboom, 2012). In peer review, the source of the proposed information is arguably given the most critique as it can directly affect the outcome of a study in terms of providing bias (Santini, 2018).

\subsection{The peer review process}

Peer review is a process that assesses the quality of an article or piece of scientific work by members of the scientific community that are of similar competence or qualification in the subject matter (Elsevier.com, 2018). In short, an author's work that is put forth for possible publication is assessed among their peers. This serves as a means of self-regulating the several and various disciplines in academia and should ideally provide high standards and credibility to quality work generated in their respective disciplines. Each discipline in academia may have specific requirements throughout their review process, but in general, they strictly adhere to common fundamental steps (Voigt \& Hoogenboom, 2012): 


\section{Acta Educationis Generalis \\ volume 9, 2019, issue 2}

- Completion of study: The complete consolidation of required information of a particular study or investigation is required preliminarily.

- Submission of study: The submission for a publication is usually in the form of an article written in the stipulated format of the desired journal.

- Review process: A journal editor receives the author's work and sends it out to experts in the same/similar field for assessment and scrutinization. This process is further broken down into either single or double-blinded reviews. The former refers to the type of review where the reviewer is aware of the author's name(s) and identity while the author(s) is/are not aware of the reviewers' identity. The latter type of review is the situation where neither author(s) nor reviewer is aware of each other's identities and the manuscripts being reviewed are essentially anonymous. The initial reviewer determines whether the article is in the scope of the journal and the editor also carries out a preliminary review of the study, before it is sent to various professional reviewers (Biomedcentral.com, 2018).

- Initial Feedback: The reviewers provide their remarks and opinions on the work presented for publication back to the author(s) (Biomedcentral.com, 2018).

- Corrections and re-submission: The authors make relevant amendments if any and resubmit the work again for consideration (Biomedcentral.com, 2018).

- Publication: Those articles that meet the standards of the journal are accepted and published into the collective body of work represented by that journal.

This review process is a time and resource consuming endeavor and can thus take a few months to over a year to complete depending on the complexity of the subject matter and the number of resubmissions the author presents (Voigt \& Hoogenboom, 2012).

Academia and research are what spearhead the endeavor of providing better healthcare, better technology and medicines that ultimately reach the patient. For example, research into vaccination has provided cost-effective intervention against infectious disease resulting in significant global health improvements and reduced mortality (Valen et al., 2011). Vaccines have been responsible for the successful elimination of smallpox, the near elimination of poliomyelitis, the worldwide decline of pneumonia (pneumococcal vaccine) and diarrhoea related mortality (rotavirus vaccine) where they save and continue to save millions of lives every year (Valen et al., 2011). Research into HIV/AIDS treatment in South Africa by the Centre for the AIDS Programme of Research (CAPRISA) has contributed to the understanding of HIV pathogenesis, prevention and epidemiology. Academic research over the centuries has led to the many of the medical breakthroughs from which modern science benefits; from something as early and serendipitous as the discovery of penicillin and subsequent antibiotic 


\section{Acta Educationis Generalis \\ volume 9, 2019, issue 2}

successes to the Sci-Fi-like use of augmented reality technology to rehabilitate patients suffering from PTSD and other such traumas, these successes can in large part be attributed to dedicated research endeavors, making them an indispensable part of the field of medicine and therapy (Fathima, Shankar, Thajudeen, 2018). Research in the academic world operates under stringent protocols that ensure the continued quality of information that comes from research institutions while simultaneously upholding fundamentals that are at the core of research i.e. discovery of the unknown, accurately acquiring and disseminating information, contributing to societal development and the continuous growth and development of our species as a whole (Pouris \& InglesiLotz, 2014; Smith, 2014). The peer review process is one such protocol that must be followed to ensure that quality information based on reputable research is added to the pool of knowledge in modern medicine. Thus, it is no surprise that much of the ethical practices that are expected in academia find their way into the practice of healthcare. The fundamental principles are very similar, i.e. to gather and disseminate important information in an ethical manner that acknowledges and respects the contributions of TK to modern medicine and is of benefit to those persons afflicted with illness that modern medicine aims to treat (Fanzo, 2015).

Reliable references are critical for reliable and accurate results and thus a large part of academic writing and the peer review process is the acknowledgment and appreciation of credible sources of information that one draws from to conduct a study or formulate an argument; by properly referring to these contributions (Santini, 2018). This is done in majority by incorporating a referencing style into the body of work or publication, the formats of which vary depending on the publisher (Deakin.edu.au, 2016). This peer-to-peer accountability has developed a culture of respect for the origin of information and pays homage to authors that have contributed to and continue to contribute to the growing knowledge pool that so many stakeholders benefit from, whether within and outside of academia (Santini, 2018). Also, culture is a provision for punishing transgressors that refuse to recognize or accredit their sources (plagiarism) which often involves a form of exclusion from many academic networks and in some severe instances, exclusion from professional academia itself (Deakin.edu.au, 2016). It is thus very realistic to strive for a professional situation whereby the individuals, research institutions or corporations that have historically and/or are presently involved in IP disputes as a result of bio-prospecting or knowledge appropriation, adhere to the same culture of checks and balances, ethical research practices, moral reciprocity, peer-to-peer accountability and consequences for transgression, that is observed in much of the academic world. In doing so, the sources of so much of the world's traditional knowledge and the sources of many indigenous plant-based therapies are accounted for and the contributions of those there from, are acknowledged and recorded in history. 


\section{Acta Educationis Generalis}

volume 9, 2019, issue 2

\section{Environmental bioprospecting, biopiracy, and intellectual property disputes}

The evolution of medicine throughout the history of humanity has had common fundamental origins. Natural products and nutraceuticals from various regions of the world have been the focal point for the development of potent and life-saving medicines used to treat a myriad of illnesses that have occurred throughout human history and even those that are observed till today. Native knowledge of these pharmacologically active natural products has been crucial in identifying those products that can be beneficial to certain illnesses (Debbarma et al., 2017; Xavier et al., 2014; Cheikhyous et al., 2011). For instance, the natural stimulant tetrahydrocannabinol (THC) found from the Cannabis sativa plant was first recorded to be used medicinally and recreationally in China and the greater Asian continent (McClatchey et al., 2009). Characterization of the compound had led to the discovery of cannabinoid receptors in the body and the subsequent elucidation of other active compounds from the plant such as cannabidiol (CBD), a non-psychoactive component of the cannabis plant. It has been clinically shown to alleviate pain, reduce anxiety, reduce blood pressure and has even shown positive outcomes in psychiatric conditions such as PTSD (Bitencourt \& Takahashi, 2018). Another example is the alkaloid compound, Reserpine, a potent depletor of monoamines in the brain such as dopamine and noradrenaline (McClatchey et al., 2009). The plant, Rauvolfia serpentina where it was isolated from, was commonly used in Asian medicine, notably by the Ayurveda system of medicine practice in India to treat hypertension, snake bites and even psychotic conditions such as schizophrenia as early as around $2500 \mathrm{BC}$ (Narayanaswamy, 1981; McClatchey et al., 2009). Only fairly recently in the 1950 s was the compound isolated and structurally elucidated but this discovery brought with it much information regarding mental illness and the treatment that is required for it particularly in conditions such as Major Depressive Disorder (MDD). These examples are to highlight how modern medicine and medicine technologies as we know them can be traced back to a more rudimentary but still scientific and valuable ethnobotanical knowledge of the environment possessed by the indigenous people of those lands.

Ethnobotanical knowledge is arguably one of the most abundant knowledge databases for the discovery of novel natural compounds (Mondal et al., 2012). TK has long been the basis of several successful drug discovery and development endeavors by many pharmaceutical companies over the past several decades (Mondal et al., 2012). Over the last few decades, the marked increase in global consumerism habits that have often become synonymous with environmental damage, have undergone a paradigm shift in the form of a sort of moral reciprocity (Ryan, 2014). This "environmental renaissance" as described by Ryan (2014) is one where humans are recognizing the implications of their accelerated resource consumption on their immediate environment and on the planet as a whole. Events such as climate change, the rising global temperature 


\section{Acta Educationis Generalis \\ volume 9, 2019, issue 2}

and pollution of land and water bodies to name few, makes it more evident that we are leaving scars on the planet, slowly killing it and ironically, ourselves in the process (Climate Change: Vital Sings of the Planet, 2018).

This "renaissance" has led to the development of a posthumanist relationship to the environment, and as described by Ryan (2014), "one where the environment is viewed as an active and creative agent to be worked with rather than as a material, substance or sight to be worked over." The author describes this attitude towards planetary health as a "moral virtue" and an essential reciprocal relationship that has huge and direct implications on our health and lifestyles (Ryan, 2014). Unfortunately, the realization of just how essential this relationship is, has come retrospectively now that we are observing the tangible and fatal effects of climate change. For example, record high temperatures as a result of global warming have already manifested in heatwaves and numerous wild fires like those observed in the North America, Greece and the Eastern Cape of South Africa (Berwyn, 2018). Record-warm ocean temperatures have resulted in increased intensity of events such as hurricanes and heavy monsoon rains resulting in heavy flooding in countries such as Japan, Indonesia, the east coast of the United States and Haiti and the droughts experienced in South Africa to name a few (Berwyn, 2018). In addition to this, flooding can destroy city sewage/drainage systems putting its population at the risk of water borne diseases. The reality that these climatic events are intensifying combined with the increase in global networking that social media provides, enables those communities affected by climate change to share important information about its effects to all corners of globe which increases the international concern and also participation in matters that pertain to climate change (Villavicencio Calzadilla, 2017).

The landmark Paris UN Climate Change Agreement that was signed on April 22nd, 2016 saw 175 nations agree to limiting the rise of global temperatures to below 2 degrees Celsius by implementing various economic regulations to limit the environmental damage (Un.org, 2018). This was a major step in the fight to decelerate the human influence on climate change and was one of the first moments in history where the international community acknowledged the harm that we as a species are doing to the planet and the rest of its inhabitants. This agreement illustrated a collective level consciousness among the nations in agreement. This awareness or consciousness of the self and the other is what needs to be achieved for us as a collective species to recognize, respect and desire to protect both human and non-human entities alike. The familiar themes of humanism and egoism in modern civilization, that have arguably been the reasons we find ourselves with the socio-political and socio-environmental issues we observe today, are undergoing a change into themes that are less subservient to the ego, less exclusionist and less human-centered into ones that cater for hybridity, inclusiveness and mutually beneficial relationships (Bolter, 2016). The new paradigm caters for entities of various natures to be 


\section{Acta Educationis Generalis \\ volume 9, 2019, issue 2}

acknowledged as a part of our reality and thus important in as far as both the human and non-human entities have the inherent and intrinsic right to exist and to do so simultaneously. The Paris Agreement acknowledges the natural environment as an independent agent that inherently has the right to exists along with all its components.

Our current developmental trajectory as a species is highly reliant on our environment's capacity to provide many of the necessities of modern societies and its many components (such as healthcare systems) and thus reciprocity ethics must become norm when undertaking projects or making policies that have environmental consequences. An ideal symbiotic situation is one where the environment is the platform for human development and that ethnobotanical knowledge, along with cooperation from indigenous/local communities, can be the medium through which modern medicine can benefit from the environment and its natural products while simultaneously giving back to the environment in the form of support for local communities/stakeholders that would otherwise be exploited (Ryan, 2014).

Many modern medications on the pharmaceutical market are a result of semisynthetic synthesis of a potent yet difficult to amass compound found in a plant. An example of this is the anticancer drug Paclitaxel commonly sold as 'Taxol', a compound derived from the bark of the pacific yew tree, Taxus brevifolia. Initially, the bark processing method, whereby the compound was extracted from the plant bark and purified, was deemed unsustainable as the tree was killed in the process and the yield of the compound was too low to meet the demands for clinical trials and subsequent market sales (Ryan, 2014). The solution was a semisynthetic iteration of the compound by using naturally occurring 10-deacetylbaccatin in the needles of the more abundant European species of the yew tree and adding a beta-lactam ring to it. This process was proved to be efficient as it involved relatively few steps and had yields as high as $80 \%$ (Jacoby, 2005). In this instance, nature product was the template that was improved upon by human ingenuity, all while consciously and proactively trying to conserve the resource that made it possible in the first place via semisynthetic production. The moral understanding here was that despite the proven benefit of the plant extract in cancer remediation, it was not possible to maximize its potential as a commercial drug without exploiting and seriously damaging the ecology surrounding the yew tree species. The understanding of environmental morality as described by Ryan (2014) in the context of the discovery of Taxol, is congruent when one considers the above mentioned posthuman approach to environmental interaction. The moral reciprocity, in the story of the development of Taxol, was ensuring the well-being of both the resource and the beneficiaries of said resource, as both parties have the intrinsic right to exist (Ryan, 2014).

Traditional indigenous North American tribes such as the Navajo and the Lumbee and the Cherokee have used plants such as American pokeweed 


\section{Acta Educationis Generalis \\ volume 9, 2019, issue 2}

(Phytolacca americana) to treat conditions such as rheumatism, arthritis and even certain cancerous conditions. Hutchens (1991, p. 351) suggests anecdotal evidence that corroborates the efficacy of a poke root poultice used by the Native Americans as a treatment for breast cancer and ulcerous cancers (Ryan, 2014). Recent research has discovered Pokeweed Antiviral Protein (PAP), a type I ribosome inactivating protein that has demonstrated significant antitumor effect in laboratory transgenic plant studies on plants inoculated with certain viral and fungal strains (Di \& Tumer, 2015; Domashevskiy \& Goss, 2015). This is a breakthrough in the ongoing battle against various types of cancers and the foundation for this breakthrough is the ethnobotanical knowledge of the indigenous communities of America. It would be in the true spirit of moral reciprocity that the efforts of the indigenous communities and the use of their environmental resources be recognized and acknowledged as valuable contributions to health sciences (Ryan, 2014).

However, in many instances this is not the case. There are several instances where global commercial exploitation of indigenous medicinal knowledge has occurred and will be discussed below in the following case analyses.

\subsection{India}

The Indian subcontinent is a large territory blessed with a variety of climates as it stretches across both hemispheres that provide environments for a plethora of plants and natural products. One such plant is the neem tree Azadirachta indica. The neem tree is a significant plant in many cultures around the country and is used for producing medicines, fertilizers and ever insecticides and has been so for millennia (Kumar \& Navaratnam, 2013). In the early 1970s, the plant began to gain noticeable popularity in the US markets as word of its versatility travelled the world and imports of the plant to the US increased (Jordaan, 2001). The neem trees ability to act as a pesticide was of particular interest to US timber importer, Robert Larson, who in 1971 observed these properties of the plant and sought to introduce it to the US market as an extract under the name Margosan-O (Shiva, n.d.). In 1985, the US Environmental Protection Agency (EPA) had granted the use of the extract as a commercial pesticide and three years later, Larson sold the patent to the chemical company W. R. Grace and Co (Shiva, n.d.). The company claimed that the pesticide was a strong and stable formulation with Azadirachtin, a major moiety of the neem as the active agent and decided to patent the neem derived substance. This led to public backlash by Indian communities as they refuted the patent assertions by Grace and Co deeming the patent an act of biopiracy. Grace and Co in turn denied the claims and reported that the methods for developing the extract was novel and thus made it amenable to patenting (Shiva, n.d.). There is an argument against W. R. Grace and Co. for unethically using the ethnobotanical information that was 


\section{Acta Educationis Generalis \\ volume 9, 2019, issue 2}

known to many native communities for commercial gain oversees without any recompense to the indigenous communities of India. This is considered a moral and ethical transgression by the Indian communities and those that sympathize with similar exploitation of indigenous intellectual property (Hamilton, 2006). Situations such as these are prevalent throughout history and still occur till date (Hamilton, 2006; Tedlock, 2006; Hamilton, 2008; Straus, 2017). In recent years, pressure from stakeholders has urged local governments to be accountable for the wellbeing and exploitation of their populations and this has prompted countries such as South Africa, Cameroon and others to establish regulations with regards to indigenous knowledge and has led to the proposition that traditional knowledge should be treated the same as intellectual property (Tedlock, 2006). This has sparked many debates as so what constitutes 'a tradition' and has led many to believe that indigenous knowledge should be protected through intellectual property frameworks, with many countries taking such initiatives (Hamilton, 2006).

When debating the case of the biopiracy of the neem plant, it is important to ask what constitutes the idea of something being 'novel'. The Indian communities would argue that the plant and the knowledge of its pharmacological versatility and range of applications was part of a millennia of pooled ethnobotanical knowledge of the plant; knowledge that was freely available to the community (Hamilton, 2008). According to Grace \& Co critics, there was no generating of new knowledge that led to their patent but simply used the already existing data on the neem tree and thus lacked true innovation (Hamilton, 2008). Grace \& Co are of the position that it is the method of extraction i.e. using ion exchange resins, that was novel and non-obvious and thus not a question of innovative legitimacy (Jordaan, 2001; Hamilton, 2008).

\subsection{Australia}

The Conospermum genus, also known as smokebush, is a family of plant species endemic to the Australian continent and is a widely used medicinal herb by the indigenous Aboriginal population for a variety of therapies (Jordaan, 2001). In the 1981, The US National Cancer Institute (NCI) had procured samples of the plant species to test for any anticancer activity but found no evidence of such (Jordaan, 2001). In the late 80's however, the samples were again tested and screened for antiviral effects and these studies reported a substance that that was effective against HIV at low blood concentrations (Jordaan, 2001; Decosterd et al., 1993). It was identified Conocurvone, a trimetric naphthoquinone extracted from the Conospermum incurvum species (Kurapati et al., 2016; Decosterd et al., 1993). In order to commercially develop their "new discovery", the Australian government licensed Amrad pharmaceuticals, now a subsidiary of 


\section{Acta Educationis Generalis \\ volume 9, 2019, issue 2}

Merck \& Co. This was further escalated when the NCI granted Amrad pharmaceutical a worldwide license to patent the substance and in return the Australian government was given royalties exceeding 100 million dollars by 2002 (Jordaan, 2001).

There have been no reports of reparations made to the Aboriginal community of Australia who are the indigenous residents of the land from which the plants were harvested. In 1993, the Australian government amended its conservation and land management Act of 1984 to include a clause that designated state control over biological resources (Jordaan, 2001). The major criticisms of the actions of both the NCI and the Australian government are the blatant lack of acknowledgement for the centuries of traditional knowledge that existed among the Aboriginal community regarding the therapeutic use of the plant species and secondly, the abuse of power by the Australian government to let a foreign enterprise take advantage of it indigenous population and its resources that are under its protection without any formal compensation.

\subsection{Cameroon}

The African cherry tree, Prunus africana, possesses very potent antiandrogenic and antiangiogenic properties and has been reported to kill tumor cells via apoptosis, prevent the development of $\mathrm{BPH}$ and alter the signaling pathways that are needed to sustain the prostate cancer cells (Komakech et al., 2017). Over $70 \%$ of the global supply of the of the bark that is used for pharmaceutical and therapeutic use comes from a small region in Mount Cameroon and is exported and extensive debarking of the trees over many years has led to the declining population of the species (Samndong, 2016). Commercial exploitation of the trade of the tree was reported to have started around the early 1970s by Plantecam medicam, a subsidiary of the French pharmaceutical company, Laboratoire Bebat, who had monopoly on the product export (Samndong, 2016). The company recruited local villagers to harvest the bark who were paid roughly the equivalent of 1 US dollar for a day's labour but was reported to have made over 150 million US dollars in 1992 selling to the European market (Jordaan, 2001; Samndong, 2016). None of these profits have been repatriated to Cameroon and neither have the effort of the labourers nor the traditional knowledge of the therapeutic benefits of the plant been recognized as contributions to the vast success that Plantecam medicam observed in the global market. 


\section{Acta Educationis Generalis \\ volume 9, 2019, issue 2}

\subsection{South Africa}

There are similar instances of biopiracy in South Africa, a country that due to its extremely diverse ecology, has been the target for many Japanese, European and American pharmaceutical companies to obtain their raw natural product materials from (Jordaan, 2001).

One example of this is the exploitation of the Rooibos plant (Aspalathus linearis), a very popular indigenous tea that has become increasingly popular as 'superfood' and health beverage due it being devoid of caffeine and at the same time rich in antioxidant flavonoids such as aspalathin and nothofagin, has low tannin content and is an antispasmodic (Canda, Oguntibeju, \& Marnewick, 2014; Jordaan, 2001). This tea is reported to have been traditionally used by the descendants of the Khoi and San people of the Cedarberg Cape for many generations and at the beginning of the 20th century had no commercial value nor was it really on the market radar (Joubert \& de Beer, 2011). Swedish botanist Carl Peter Humberg in 1772 was historically recorded to have instigated biopiracy of the tea by learning of its benefits from the Khoi-San people and began marketing it to Germany under the name "Rooibos' or "Massai tea" (Amusan, 2014). In 1904, the tea was made popular in the market by Russian immigrant Benjamin Ginsberg, a merchant of Clanwilliam, who with the help of Dr. P. le Fras Nortier (also of Clanwilliam) cultivated the crop at a commercial scale (Amusan, 2014). The rapid expansion of land utilization for this crop during this period threatened the biodiversity of the Greater Cederberg region and as a result, the Rooibos Tea Control Board was established in 1954 to regulate producer prices (Jordaan, 2001). In 1970, South African author and cosmetic influencer, Annique Theron published her book Allergies: An amazing discovery on rooibos which made the plant gain notoriety in the western world (Amusan, 2014). She registered her cosmetic company, Forever Young, in America where she produces cosmetics with rooibos tea additives which further popularized the plant leading her to file a trademark application for Rooibos with the US Patent and Trademark Office (USPTO) (Amusan, 2014). South African company, Rooibos Limited, challenged the patent as the deemed the export of the plant product under the name 'Rooibos' was a violation of Intellectual Property law and sales in the US should be curtailed if it was not classified as under a generic name, a claim that was backed by the South African government and the Western Cape Province (Amusan, 2014). After it was trademarked in the U.S., Theron reportedly sold the patent under what appears to be dubious circumstances to an American friend, Burke-Watkins, co-founder of Burke International Pharmaceuticals, for $\$ 10$ in 2001 (Amusan, 2014). Rooibos Limited in South Africa aimed to combat this by attempting to register the product with the USPTO as "Rooibos the Red Tea" which caused backlash by Burke International as the product still contained the word 'rooibos' in it. After nearly a decade of legal battles the matter was settled out of court and both parties used the word 'rooibos' in conjunction with other words/symbols such as 


\section{Acta Educationis Generalis \\ volume 9, 2019, issue 2}

'TM' in 2006 (Amusan, 2014). Rooibos limited also registered the product with Benelux Office for Intellectual Property (BOIP) to gain a stronger foothold in the market (Amusan, 2014). All the while this is was happening very little was discussed about the ramifications of exploiting rooibos tea would have on the indigenous Khoi-San community. Recognition of the traditional knowledge of the rooibos plant as the basis for the large success observed went unaccounted for and these communities as a result have fallen victim to the harsh ramifications of world trade policies that protect products registered under licence. Policies do not seem to account for the lineage of the information that contributes to knowledge that produced and popularized the products under licence, making it difficult for the indigenous owners of the intellectual property to seek justice in the form of reparations or compensations (Amusan, 2014).

Over the years the South African Government and the Khoi-San people have together aimed at developing protocols to ensure that natural resources indigenous to South African communities is protected and said communities or their natural resources are not exploited commercially or academically. The San code of research ethics is one such proposal by the South African San Institute and this document highlights 5 core ethical principles they expect persons of interest to follow when conducting research or bioprospecting studies on their indigenous land (South African San Institute, 2017). Once again, these guidelines have adopted some facets of Gillonian Principlism as part of its core values and are as follows:

- Respect: Respect for indigenous persons and their community, their culture and history and their sensitivities. Respect for culture also includes respect for the communities relationship with the environment in that any contributions made by the community or the environment on which the research is conducted, must be acknowledged. This aspect of the code of conduct also gives provisions for mutual accountability.

- Honesty: Honesty on behalf of those parties wishing to carry out research or bioprospecting on San land is deeply valued and expected. Intentions of the proposed research must be transparent and non-malicious. This code gives provisions for the language that must be used in agreements between the San and the researcher i.e. clear and non-academic, makes provisions for informed consent by the local community members to partake in research studies so they are not exploited.

- Justice and Fairness: This code of ethics describes the moral obligation of the researcher to meaningfully involve the San community in the proposed study which includes learning the benefits of the research and what the community can expect in return. This code gives provisions for means of compensation in the form of co-research opportunities, sharing of skills and technology and also monetary compensation. As part of exacting justice on breaches of the code, the San will use dispute resolution mechanisms which will include refusal to conduct future research on San lands. 


\section{Acta Educationis Generalis \\ volume 9, 2019, issue 2}

- Care: This code of conduct outlines how research conducted on San land must be aligned to local needs and should in some way aim to improve the lives of the local community. 'Care' implies that the care for the community and the physical environment must be considered. 'Care' also includes the acceptance of the San people for who they are which includes their social and cultural norms.

- Process: The code of conduct stipulates that researchers need to follow protocols set out by the san carefully in order for the ethical codes of conduct to work effectively. The San Council manages the protocols that will set specific requirements for various steps of the research to which the researchers must agree to. This is in order to oversee that the community and its environmental resources are not exploited (South African San Institute, 2017).

The Khoi-San community is acutely aware of the bioprospecting transgressions that can happen when working with large corporations or participating in research endeavors and has thus taken steps to ensure the protection and continued development of their human and non-human resources.

\section{Economic cost-utility philosophy and associated inconsistencies - Utility in healthcare}

Utilitarianism has been made synonymous with the phrase "the ends justify the means" in that we should in all circumstances make choices that produce an overall net positive for all persons involved (Mack, 2004). This principle is about maximizing utility, in other words it is a philosophical principle focused on the efficiency of systems in maximizing desirable outcomes. This principle is strongly adopted throughout the multifaceted system that is healthcare (Mack, 2004). From multi-billion-dollar pharmaceutical enterprises to community level clinical practice, the understanding that healthcare is an expensive economic expenditure is universal thus results in efforts to make the system as efficient as possible in providing the most wellbeing at the least cost (Mack, 2004). For example, the formulation of essential medicine lists is a calculated pharmacoeconomic process that involves assessing several parameters of economic efficiency including cost-minimization, cost-effectiveness, costbenefit and cost-utility (Apps.who.int, 2018). The most philosophically relevant and arguably most challenging of these is the cost-utility analysis because the outcomes of these decisions are measured in terms of health status (a utility) or an improvement thereof as perceived by the individual; an otherwise seemingly subjective quantification (Apps.who.int, 2018). Despite this, efforts have been made to express the value for money invested into healthcare service in terms of a single type of health-related outcome and that is the Quality Adjusted Life Year or (QALY) (Apps.who.int, 2018). According to the WHO, an increased quality 


\section{Acta Educationis Generalis}

volume 9, 2019, issue 2

of life is expressed as a utility value ranging from 0 (a state of death) to 1 (perfect quality of life). Assessing a potential health benefit of one treatment versus another, say for example a chronic drug therapy vs a surgical procedure, becomes a matter of how well each intervention reflects as a QALY score (Apps.who.int, 2018). This process of determining health benefit outcomes has been criticized for attempting to assign an accurate numeric value to qualitative experiences, and that this value empirically quantifies individual outcomes as experienced by the individual (Mack, 2004).

The applications of normative utility philosophy in healthcare systems do not always translate from their ethical tenants. The inconsistencies lie in determining what constitutes utility and how to objectively aggregate widely different interests in order to accurately determine what is 'maximal value' and, ultimately, what constitutes a good/ethical action (Mack, 2004). In utilitarian healthcare, consequences or outcomes of care can be interpreted in various ways; one of which is how an outcome results in a particular desirable health state and how it meets individual needs. Another is how an outcome may be thought of as the extent to which the health gap in a population might be narrowed, however the former is the more common interpretation of the two due to the fact that healthcare is commonly dispensed at an individual level with a physician (Mack, 2004). Thus, the notion that good ethical actions are those that maximize the benefit of the population, at some (or several) level(s), comprises the desires and convictions of the individual (Mack, 2004). Such is the idea of the Pareto principle which stipulates that $80 \%$ of healthcare costs come from $20 \%$ of those in need of health services also known as the '80/20 rule' (Naoum et al., 2016); it is a utility based principle that advocates for concentrated effort on those endeavors or interventions that have the greatest impact (Institute for Healthcare Improvement, 2019). The ethics of utility have been criticized for being overly 'collectivist' in nature in that the goal of maximizing a collective measure of every individual utility does not take into account for the distribution of said utility in the population (Mack, 2004). This philosophy implies and assumes that sacrificing some individual utility at the benefit of the larger collective is something every individual is prepared to do at the expense of their own aspirations and intentions and is in essence a moral justification for limiting individual rights (Anzinger, 2004). Utility has parameters that do not account for the diverse experiences of welfare and wellbeing of its constituents but has to subscribe to an impersonalized version of the welfare of the collective. This doctrine's limitations include conceptualisation and acceptance of autonomy, respect for persons and justice, as crucial facets of its experience and is thus ethically inconsistent with the moral philosophy that guides the practice of professional healthcare service and the associated corporate institutions that they work alongside with (Mack, 2004). 


\section{Post-humanism as an alternative philosophical anthropology to utility and deontology ethics}

\subsection{Autonomy and agency}

Autonomy and agency are words that are used quite anonymously but have different connotations when discussed as philosophical concepts. If all known entities are objects, then any object is any entity to which a mental can be ascribed. A spoon, for example, is an object that has the ascribed mental state of a spoon so long as it serves the purpose of a spoon i.e. to stir, sip from, etc. A spoon (or any object) is thus then an agent only if it satisfies the conditions of a purpose that is imposed on it. However, this purpose is dependent on the mental state we ascribe to other objects and can thus alter what a spoon represents in certain contexts; in other words, agency is transient so an agent can revert to being a passive object should it lose its ascribed mental state. An agent that is able to intrinsically generate its own goals and whose agency is not depended on the agency of other entities, is said to be an autonomous agent (Luck \& d'Inverno, 1995). Autonomous agents possess motivations and an acuity to evaluate behavior as they relate to said motivation and are also able to perceive phenomena that are not related to their own motivation. Autonomy is central to many other philosophical ontologies because they acknowledge that autonomy is the basis of intrinsic motivation for any endeavor and the reason of any observable human behavior (White, 1959).

Thus, utilitarianism does not do justice in accurately accounting for the human condition, especially when examining its ethics because this moral position ultimately reduces the individual to a unit that is indistinguishable from any other. The Greatest Happiness Principle or the general concept of utility assumes that all motivations are collective and autonomous agency is irrelevant because the only outcome is the satisfaction of an impersonal collective motivation that the individuals that comprise the collective are willing to synchronously work towards (Luck \& d'Inverno, 1995). It essentially assumes that the removal of autonomy and the subsequent compromise of individual aspirations and motivations is consensual and ultimately to the benefit of the individual in as far as the individual benefits the collective wellbeing. The idea of utility as put forth by consequentialist philosophy cannot simultaneously account for the wellbeing of the collective and the autonomy of all of its individual constituents as the two notions fundamentally contradict each other. Individual aspiration, at whatever cost, are sacrificed for greater collective benefits for any action to be deemed ethical in utility ethics. In a utilitarian system, autonomy is not desirable nor functional, thus the individuality and the actualization of the self are things that would take away from the collective and, as a result, the greatest benefit goes unachieved and those autonomous/self-serving action/decisions would constitute ethical wrongdoing. It is thus a bold assumption within utility philosophy that a 


\section{Acta Educationis Generalis \\ volume 9, 2019, issue 2}

human being must and is ready to abandon autonomy, conscious and/or unconscious intrinsic egoism and the survivalist self-servitude of our nature in order to satisfy a collective and impersonal objective whose undertaking is supposed to reflect a degree of goodness or wrongness of our actions.

\subsection{Environmental ethics}

The increasingly observable changes in our environment, as direct or indirect impact of human activity, has made environmental ethics a spotlight discipline in philosophy that aims at studying the moral relationship humans have with the biosphere and nature's abiotic components (Brennan \& Lo, 2002). Environmental ethics and ecological studies are challenges to the mainstream 'Western' anthropocentric ontology of human-environmental relationships where even notable philosophers such as Aristotle was famously quoted stating "nature has made all things specifically for the sake of man" and that "the value of non-human things in nature is merely instrumental" (Laal, 2009). Aristotle's take on the relationship is that of an utilitarian since non-human entities are merely an "instrument" or a means to be used to benefit and achieve man's ends. Even Immanuel Kant in his work Lectures in Ethics: Duties to Animals and Spirits suggests that cruelty to a dog may increase the likelihood of a person developing an indifference to human cruelty implying that the act of cruelty to a dog is instrumental to a more significant cruelty to humans and not intrinsically wrong but only in as far as it affects human beings (Brennan \& Lo, 2002). Thus, classical "Western" philosophy and religious canon provide an inadequate and almost static understanding of ecology and its dynamic natural relationships. Aristotle, Bentham, Sidgwick, and many other traditional ethicists advocated for an anthropocentric existence that places a heavy burden of demand from the environment with very little or no consideration and inclusion for its protection, finity of resources, exponential human population growth, and ultimate selfinjuring exploitative practices (Brennan \& Lo, 2002). Even the book of Genesis in the Old Testament of the Bible describes God telling Adam and Eve to "be fruitful and multiply, fill the earth and subdue it and have dominance over every living thing that moves upon the earth", a notion synonymous with the moral fundamentals of utilitarianism (Bible Gateway, 2019).

\subsection{Deontological approach}

Traditional deontological theories on environmental ethical issues hold the position that an action is 'right' or 'wrong' not because of its consequences but because of the intrinsic 'rightness' or 'wrongness' of said action(s). However, deontology limits this to human beings only (Anzinger, 2004). As stated by Brennan and Lo (2002), animal rights activist and many proponents of environmental egalitarianism in the early 1980s formulated such deontologybased theories that gave qualitative value to the experiences of animals based on the intrinsic criteria of "subject-of-a-life". This suggests that for something to 


\section{Acta Educationis Generalis \\ volume 9, 2019, issue 2}

have intrinsic value and thus be a "subject of a life" a subject must have senseperception, beliefs, desires, motives, sense of self and others, a sense of time and other facets of perception). Thus, it would be our moral duty as rational sentient beings to respect this right and to do no harm to other subjects-of-a-life. It recognizes all biological life as sentient and more significantly, autonomous, which is not always the case. The criticism with this 'biocentric' stance is that it is too individualistic in its moral approach to account for the conservation concerns for ecological "wholes" - a 'whole' being a species or other descriptive classification of collective of organisms. That is to say that it does not adequately consider how various natural systems (biotic and abiotic) operate as self-contained yet interdependent collectives (in that species are self-contained wholes/aggregates but their existence is linked to the existence of other selfcontained species of organisms) and how in nature, non-human (biotic) life exhibits more collectivist interactions (Brennan \& Lo, 2002).

Virtue ethics is the third major field of normative ethics that argues that utilitarian and deontological philosophy is not robust enough in defining concepts such as "goodness" and "badness" and that morality involves more than just concepts of duty or utility but other more abstract virtuous phenomena such as kindness, greed, justice or sincerity. Virtue ethical theory is criticized for not being able to explain the convictions/rationality for human behavior but rather serves as a guideline to living a "virtuous human life" which is in itself is a central concern of the agent (human). Virtues such as benevolence, courage and trust are said to be integral to a flourishing human experience and are simultaneously influenced by needs and desires thus not always motivated by a sense of duty or maximum utility. Considering that this stance is arguably anthropocentric and does not suggest of how the non-human elements of nature are to be concerned for from a moral standing, it does suggest that a 'flourishing' human experience requires the moral capacity to understand and value love, respect, reciprocity and care for the non-human natural world as an end in itself (Brennan \& Lo, 2002).

\subsection{Contextualizing post-humanism}

As mentioned earlier in the chapter, posthumanism is the current paradigm shift with which much of our environmental consciousness has arisen from. 'Posthuman' implies a necessary degree of self-awareness that is required to simultaneously acknowledge the existence and desires of the 'self' and acknowledge the independent and autonomous existence of entities that are not the 'self'. Many post-humanist theorists have proposed that the ideology is critical to understanding what it means to be 'human' and that it also provides a philosophically based but practical approach to navigating the murky waters of the human-environmental interactions. According to Whatmore (2006), posthumanist approaches to issues such as environmental conservation require us to understand the ontology of beings, i.e. understand the essence of their being in 


\section{Acta Educationis Generalis \\ volume 9, 2019, issue 2}

relation to our own existence. Post-humanist thinking is different from humanist ideology in that humanism centres around individuality, hierarchical existence and an almost isolation/detachment of the self from the surrounding environment, while posthumanism is centred around the idea of interconnected thinking and that considers all experiences as mixed, relative and relational. In practice posthumanism is a shift in the mentality of the humanist ontology of singular human rights to post-human mentality of existential rights i.e. the rights of any existing entity (such as the environment) (Datta, 2016). In summary, humanist conceptions of reality place human beings at the top of the ontological pyramid, while posthumanist conceptions aim to dethrone the self-centredness of the human experience and locate it in a more horizontal ontology with respect to our place in the world and greater universe.

\subsection{Recognition of non-human rights and the protection of non-human agents}

Whatmore (2006) states that "relationships are considered a political conception which can connect us with everything..." and it is this ontological idea that serves as the moral foundation and rationale for protecting IP rights of indigenous TK: the posthumanist approach to socio-political and socioenvironmental issues focuses on the relationships of the parties involved and the mutual accountability they are morally obligated to (Datta, 2016). In contrast, humanist based socio-political approaches aim to serve the best interests of the self or the privileged few, while exploiting those resources (human and nonhuman) to achieve said interest(s). There are elements of utilitarianism that influence the ontological hegemony humans dictate in the natural world where the 'greatest good' is that which increases the collective benefit.

For example, the exploitation of natural resources like water by companies such as Nestlé has been rampant throughout the last 20 years and still persists till the present day (Glenza, 2018). In a recent 2017 investigation, Nestlé had been found to be exploiting the natural water aquifers of Evart, a small town in Michigan, U.S.A., only 2 hours away from the recently infamous town of Flint, Michigan. Nestle is reported to pump nearly 100,000 times more water than the average Michigan resident uses and Nestlé is only paying a comical \$200 administration fee per annum to the state of Michigan to extract water from the aquifers. The residents of Flint, Michigan, are being exposed to elevated levels of lead in their tap water since the government, in an effort to save money, switched the city's water supply to the corrosive Flint river (Glenza, 2018). This has resulted in an increase of fetal deaths by 58\% during the period but despite this, residents of Flint still pay upwards of $\$ 200$ per month for tap water service delivery that cannot be used for consumption or personal hygiene. In a statement by Flint resident and activist, Gina Luster to the Guardian news outlet, she reported that she was forced to bathe her child in lukewarm bottled water emptied into a tub as a result of the harmful Flint tap water. The residents of Michigan see Nestle's bottling plant, Flint's tainted water supply and the mass 


\section{Acta Educationis Generalis \\ volume 9, 2019, issue 2}

water shutoff to neighboring city of Detroit as conspiracy to develop a system of water resource profiteering that "puts the water into private hands" as put by Gina Luster (Glenza, 2018). This is an instance of corporations adopting a humanist approach to socio-economic dynamics where a few persons/entities in power are utilizing what is otherwise a public, natural resources to the benefit of themselves or a select few at the expense of the health and safety of the larger community. The philosophical position Nestle has chosen to subscribe to in this matter is that of anthropocentrism - a hierarchical ontological pyramid where humans and human interests are actualized at the expense of the natural environment and, consequently, those entities whose livelihoods very existence closely and intimately depend on (Kopnina et al., 2018). Corporate entities such as Nestle argue that the greatest happiness/benefit is not found in the cessation of its actions/services that prevent Nestle from producing products to meet consumer demands or actions that would in some way bring about instability and distress to stockholders, employees, consumers and the like. The desirable outcomes or consequences of this moral philosophy account only for the individuals (stakeholders) or rather the collective of individuals (the corporate board) that comprise the benefiting majority and not necessarily for the individual autonomous constituents. In essence it takes on the principles of utilitarianism that advocate for achieving what is deemed morally good (that which benefits the greatest number of people and maximizes utility) irrespective of the cost to the individual/the self.

At the other end of this spectrum we find social responsibility shown by large corporations in ways that ensure mutual accountability and mutual benefit to all relevant stakeholders and not solely to company shareholders. The term "stakeholder" takes the perspective that societal members are individuals that have an identity and a stake, claim or interest in the operations of the corporation (Velamuri \& Venkataraman, 2007). The stake may be a legal one in which an individual is explicitly or implicitly contracted by the business and is carried out in the capacity of an employee, owner or customer or it can also be a moral stake where the societal group in question asserts their rights to fair treatment, due process or compensation for various damages such as an Intellectual Property claim (Carroll, 1991). A corporate example of this is the pharmaceutical company GSK, which in 2012, was involved in one of the biggest healthcare fraud scandals in history where the company pleaded guilty to promoting drugs for unapproved uses and failing to report safety data about a diabetes drug to the FDA and ultimately settling the case on a $\$ 3$ billion agreement (BBC News, 2012). Fast forward to March 2016 and the very same company announces that it will no longer file drug patents in the lowest income regions of the world in an effort to increase patient access to medicine and health services (Time, 2016). In addition to this the company has partnered with the NGO "Save the Children" to train local community members in health-related education, how to properly administer vaccines, screen for certain conditions and dispense basic medical 


\section{Acta Educationis Generalis \\ volume 9, 2019, issue 2}

services (Time, 2016). In Botswana, the GSK subsidiary, ViiV Healthcare, entered an agreement with the government to provide the HIV drug Tivicay (Dolutegravir) as part of the national outreach program for screening and management of HIV patients (Time, 2016).

In this example, GSK was shown to have behaved humanistically and with utilitarian ideals when it was convicted of knowingly promoting the use of unregulated medicines from which it profited (BBC News, 2012). However, in the latter example, GSK displayed moral and ethical values consistent with a post-humanist ontology whereby corporate social responsibility was the desired theme of their outreach initiative in Botswana. Corporate entities, as illustrated above, are capable of actions formed on either end of the moral spectrum be it self-serving and humanist or community oriented and post-humanist. The agendas of these organizations is primarily to maximize the profits from selling their products but the growing trend in many of the communities they are based is an increasing expectation of these corporate entities to be more socially responsive and accountable to all their constituents that have a claim or stake in the activities of the company within their community (Forbes, 2017).

The rapid developments in technology from around the world are reshaping the way everyday life is lived and play a greater role in the socio-political, cultural and environmental facets of our society. Developments in automated services such as driverless cars, voice-activated in-home personal assistants, artificial intelligence, pharmaceutical advancement, robotic surgeries and robotic physical augmentation are becoming more incorporated and accepted into our societies worldwide and as a result the line between the conventional humanist binaries of 'human and non-human' or 'culture and nature' become more and more blurred (Forlano, 2017). Thus, their contribution and intimate involvement in our existence must be acknowledged which requires us as humans to recognize them as entities with agency. For example, the Maori tribe of New Zealand after over 140 years of negotiation with the New Zealand government, won a legal battle to grant the Whanganui river the status of ancestral personhood giving it the same legal rights as a citizen of New Zealand (Roy, 2018). The field of biotechnology has shown advancements in gene editing using CRISPR/Cas9 technology that is able to alter genes in many organisms to treat disease or predetermine it. Advancements such as these challenges us as a species to ask difficult ethical and moral questions such as what it means to be human? What is identity? How will the assimilation of non-human entities into everyday human life alter who or what we are and thus ultimately what will it mean to be human in the future? (Roy, 2018). It is also important to remember that when discussing these ethical post-human dilemmas that consideration of the non-human entities must be made as well, thus any technological designer or research endeavor that needs to navigate these ethical problems must ask itself certain questions as suggested by Roy (2018): 


\section{Acta Educationis Generalis \\ volume 9, 2019, issue 2}

- "Who or what are the users of said designed technology and for whom or what should the design be desirable?" The user here could mean any entity weather human/animal or an individual or networked organization that must be considered as an entity with rights.

- How will agency and power distribution be carried out across human, machine and/or natural ecological systems? This consideration is critical as it determines how we as human beings will interpret our relationships with nature and technology when these entities are added to the power dynamic between man and the nature.

- What knowledge, stakeholders and partnerships are required of the designers or researchers to address these conundrums. This consideration is very important when dealing with stakeholders involved in IP disputes about TK. It requires that all parties both human and environment be considered and given agency.

- How are/will the ethics of post-human ideology be reflected and embedded throughout the design process of the technological instrument or research endeavour, i.e. will these ethical values be incorporated into societal framework and if so how? And also, what if any existing or future policies will they influence? (Roy, 2018)

As was mentioned above, in most societies around the world, morals and ethical values influence the laws that are enforceable in a society (to varying degrees) and thus they are very important when forming legal frameworks that seek to justly govern a population/community and resolve inevitable disputes. Traditionally, the legal framework that aims to carry out dispute resolution between persons or persons and corporate entities and does so with the understanding that each party is a self-contained entity with rights (Masango, 2010). This means they are both entitled to a due process that allows them to contest disputes over a claim to property for example with opposing convictions as in the case with IP dispute resolution with indigenous holders of TK. Parties on either side of an IP property dispute have their opposing reasons for challenging the proprietary status of the product as either side tries to claim royalties from the market successes of said disputed product (Masango, 2010).

The idea of Intellectual Property (IP) covers four unique types of non-material property.

i. Patents: The rationale for patent protection is to enable the patent owner to prevent other authors/persons from "making, selling or using the subject matter of the valid patent" (Masango, 2010).

ii. Copyright: The rationale for copyright protection is "to uphold the economic and moral rights of the copyright owner. This includes the right of the owner to prevent others from financially benefiting from their work (Masango, 2010). 


\section{Acta Educationis Generalis \\ volume 9, 2019, issue 2}

iii. Trademarks: Trademark protection is to prevent a second party from appropriating or capitalizing on the value of a successful/well-known brand, trademark or servicemark (Masango, 2010).

iv. Trade secrets: The basis for a trade secret is to protect a product without its registration i.e without procedural formalities and this ground rests "on the commercial value of the matter on the claimant." (Wipo.int, 2018)

Indigenous TK includes knowledge and identification of specific plants and their properties, harvest practices, the mythos (superstitions and traditional stories) surrounding the traditional use of the plant/product, the rites and practices they are used for (Masango, 2010). Rites, rituals, and mythos cannot be protected under IP laws but the knowledge that is up for protection is that which deals with the specific use of the plant, plant identification, side effects, etc. Masango (2010) illustrates scenarios in which indigenous TK can be protected under the above-mentioned categories for IP. For example, indigenous TK can be protected under patent protection facets because it deals with the financial exploitation of the medicinal properties of the indigenous plant by bioprospectors from other countries - as it was the case with the Khoi-San people of South Africa and the appetite suppressant/anti-obesity drug obtained from the Hoodai gordonii. The plants were claimed to possess anorectic effects in anecdotal evidence from traditional knowledge of the Khoi-San which prompted the South African Council of Scientific and Industrial Research (CSIR) to hop on the opportunity to market this potentially profitable product. A product called 'P57' was patented by the CSIR and then the licence sold to English company, Phytopharm in 1997. The patent was then sold to American giant Pfizer pharmaceuticals for \$25 million dollars in 2002 all the while excluding the indigenous people of the Kalahari from participating in important conversations and negotiations and only became aware of the success of the plant product though foreign media coverage (Masango, 2010). The Khoisan, after many years of negotiations and legal battle with Pfizer, ultimately signed a benefit-sharing agreement with the CSIR in 2004 where the CSIR agreed to pay the Khoi-San $8 \%$ of all milestone payments it receives from Phytopharm (UK) and an additional $6 \%$ of all royalties that the CSIR receives once the drug is made commercial (Sciencedirect.com, 2010). The CSIR also agreed to involve the local community in future bioprospecting studies and provide them with study bursaries and scholarships to better educate and develop their space (Sciencedirect.com, 2010). Patent protection can thus benefit indigenous communities such as the Khoi-San community in that it is able to provide them with an avenue for recognition and compensation for knowledge that was unethically acquired and used by a competing entity.

When looking at the bigger picture, the successful benefit sharing agreement between the CSIR and the Khoi-San is an important milestone in the very intricate system of patent exclusivity and biopiracy because it showed that 


\section{Acta Educationis Generalis \\ volume 9, 2019, issue 2}

despite the law supporting the legality of the exclusive sale and profiteering of the Hoodai plant by international companies, the CSIR was able to acknowledge the perspective of the Khoi-San in that they had a legitimate claim to the original knowledge database on the plant and its use. This illustrates a degree of selfawareness on the part of the CSIR and the members of the indigenous community, to come to a mutual understanding of their common goal (i.e. recognition and profit from knowledge) and form a relationship that can facilitate mutual benefit to that common end. This agreement ensures that the local community and the equally important environment that supports it are given the right to self-development, dignity in how they and their environment are treated, respect for their long history, their traditions and, of course, the traditional knowledge of their local medicinal plant life. It serves as an example of post-humanistic ethics carried out within the South African legal framework. This could suggest that this new philosophical ontology has the potential to shape policies that often-marginalized indigenous practitioners of TK around the world and can provide them with a more inclusive platform to contribute to modern medicine and benefit from the success of potential breakthroughs (Masango, 2010).

\section{Conclusion}

In practice, posthumanist ontology is viewed as a relational responsibility to the community and their environment (Datta, 2016). Thus, any entities that seek to utilize the indigenous plant knowledge of an area must first develop a relationship with the environment/resource they wish to investigate. This is best done with the aid of persons that have an already established relationship with the environment such as indigenous community healers, village chiefs, elders and traditional doctors. They must be recognized as part of the indispensable human resource team that is required for bioprospecting and novel drug discovery R\&D. It is thus important that the sentiments for their culture and practices be respected and their contributions acknowledged in the research endeavor and adequately compensated for. Utilizing post-humanism in modern science is a challenging concept to materialize but one that can be overcome through traditional community-based science education where the goal is to reconfigure the mentality and attitudes we have towards nature and natural resources in a way that also appreciates diversity and honors the relationships between various participants (human and the non-human) looking to exists in a common space (Datta, 2016). This very last quotation can be a legacy for educators, philosophers and scientists worldwide, as it can inspire them to be and make others aware of this challenge in modern world because that manifests educated behaviour and ethical attitude towards culture/other cultures and natural resources. 


\section{Acta Educationis Generalis \\ volume 9, 2019, issue 2}

\section{References}

Alexander, L., \& Moore, M. (2016). Deontological Ethics. Retrieved from https://plato.stanford.edu/entries/ethics-deontological/

Amusan, L. (2014). The plights of African resources patenting through the lenses of the World Trade Organisation: An assessment of South Africa's rooibos tea's labyrinth journey. African Journal of Traditional, Complementary and Alternative Medicines, 11(5), 41-47.

Anzinger, D. (2004). Ethics and Natural Resources. Retrieved from https://courses.ecampus.oregonstate.edu/for365/two/EthicsandNaturalResou rces.htm

Apps.who.int. (2018). Introduction to Drug Utilization Research: Chapter 4: Economic aspects of drug use (pharmacoeconomy): 4.5 Cost-benefit analysis. Retrieved from http://apps.who.int/medicinedocs/en/d/Js4876e/ 5.5.html

Azétsop, J., \& Rennie, S. (2010). Principlism, medical individualism, and health promotion in resource-poor countries: can autonomy-based bioethics promote social justice and population health? Philosophy, Ethics, and Humanities in Medicine, 5(1), 1-10.

Baker, A. (1997). Social pluralism. Australia: A. J. Baker.

BBC News. (2012). GlaxoSmithKline 'guilty of fraud'. Retrieved from https://www.bbc.com/news/av/world-18684350/glaxosmithkline-to-pay3bn-in-us-drug-fraud-scandal

Berwyn B. (2018). This Summer's Heat Waves Could Be the Strongest Climate Signal Yet. Retrieved from https://insideclimatenews.org/news/ 27072018/summer-2018-heat-wave-wildfires-climate-change-evidencecrops-flooding-deaths-records-broken

Bible Gateway. (2019). Bible Gateway passage: Genesis 1:28 - New International Version. Retrieved from https://www.biblegateway.com/ passage/?search $=$ Genesis $+1 \% 3 \mathrm{~A} 28 \&$ version $=\mathrm{NIV}$

Bittencourt, R., \& Takahashi, R. (2018). Cannabidiol as a therapeutic alternative for post-traumatic stress disorder: from the bench research to confirmation in human trials. Frontiers in Neuroscience, 12, article 502. https://doi.org/10.1186/1747-5341-5-1

Biomedcentral.com. (2018). Biomedical Central. Retrieved from https://nutritionj.biomedcentral.com/submission-guidelines/peer-reviewpolicy

Bolter, J. (2016). Posthumanism. The International Encyclopedia of Communication Theory and Philosophy (pp. 1-8). https://doi.org/10.1002/9781118766804.wbiect220

Brennan, A., \& Lo, Y. (2002). Environmental Ethics. Plato.stanford.edu. Retrieved from https://plato.stanford.edu/entries/ethics-environmental/ 


\section{Acta Educationis Generalis \\ volume 9, 2019, issue 2}

Burger, J. (2009). Defining culture in Animals. The Question of Animal Culture. Kevin N. Laland and Bennett G. Galef (Eds), Harvard University Press, 2009. BioScience, 59(11), 1001-1002.

Canda, B., Oguntibeju, O., \& Marnewick, J. (2014). Effects of consumption of rooibos (Aspalathus linearis) and a rooibos-derived commercial supplement on hepatic tissue injury bytert-butyl hydroperoxide in Wistar Rats. Oxidative Medicine and Cellular Longevity,1-9.

Carroll, A. (1991). The pyramid of corporate social responsibility: Toward the moral management of organizational stakeholders. Business Horizons, 34(4), 39-48.

Cheikhyous, A., Mapaure, I., \& Shapi, M. (2011). The use of some indigenous plants for medicinal and other purposes by local communities in Namibia with emphasis on Oshikoto region: A review. Research Journal of Medicinal Plant, 5(4), 406-419.

Climate Change: Vital signs of the planet. (2018). Climate Change Causes: A Blanket around the Earth. Retrieved from https://climate.nasa.gov/causes

Collinsdictionary.com. (2018). World view definition and meaning/Collins English Dictionary. Retrieved from https://www.collinsdictionary.com/ dictionary/english/world-view

Datta, R. (2016). How to practice posthumanism in environmental learning: Experiences with North American and South Asian indigenous communities. IAFOR Journal of Education, 4(1), 52-67.

Deakin.edu.au. (2016). Why Reference? Retrieved from http://www.deakin. edu.au/students/studying/study-support/referencing/why-reference

Debbarma, M., Pala, N., Kumar, M., \& Bussmann, R. (2017). Traditional knowledge of medicinal plants in tribes of Tripura in Northeast India. African Journal of Traditional, Complementary and Alternative Medicines, 14(4), 156-168.

Decosterd, L., Parsons, I., Gustafson, K., Cardellina, J., McMahon, J., Cragg, G., Murata, Y., Pannell, L., \& Steiner, J. (1993). HIV inhibitory natural products. 11. Structure, absolute stereochemistry, and synthesis of conocurvone, a potent, novel HIV-inhibitory naphthoquinone trimer from a Conospermum sp. Journal of the American Chemical Society, 115(15), 6673-6679.

Di, R., \& Tumer, N. (2015). Pokeweed antiviral protein: Its cytotoxicity mechanism and applications in plant disease resistance. Toxins, 7(3), 755772 .

Domashevskiy, A., \& Goss, D. (2015). Pokeweed antiviral protein, a ribosome inactivating protein: Activity, inhibition and prospects. Toxins, 7(2), 274298.

Draaisma, D. (2017). Perception: Our useful inability to see reality. Nature, 544(7650), 296-296. 


\section{Acta Educationis Generalis \\ volume 9, 2019, issue 2}

Elsevier.com. (2018). What Is a Peer Review? Retrieved from https://www.elsevier.com/reviwers/what-is-peer-review

Fanzo, J. (2015). Ethical issues for human nutrition in the context of global food security and sustainable development. Global Food Security, 7, 15-23.

Farooq, I. (2015). Lengthy peer review times: What should be done? International Journal of Emergency Mental Health and Human Resilience, $17(2), 485$.

Forlano, L. (2017). Posthumanism and design. She Ji: The Journal of Design, Economics, and Innovation, 3(1), 16-29.

Forbes. (2017). The 10 Companies with The Best CSR Reputations in 2017. Retrieved from https://www.forbes.com/sites/karstenstrauss/2017/09/13/ the-10-companies-with-the-best-csr-reputations-in-2017/\#22bc4b1d546b

Gillon, R. (1994). Medical ethics: four principles plus attention to scope. BMJ, 309(6948), 184-188.

Glenza, J. (2018). Nestlé pays $\$ 200$ a year to bottle water near Flint - Where water is undrinkable. Retrieved from https://www.theguardian.com/usnews/2017/sep/29/nestle-pays-200-a-year-to-bottle-water-near-flint-wherewater-is-undrinkable

Hamilton, C. (2006). Biodiversity, biopiracy and benefits: what allegations of biopiracy tell us about intellectual property. Developing World Bioethics, 6(3), 158-173.

Hamilton, C. (2008). Intellectual property rights, the bioeconomy and the challenge of biopiracy. Genomics, Society and Policy, 4(3), 26-45.

Hpcsa.co.za. (2016). General Ethical Guidelines for the Healthcare Professions. Retrieved from http://www.hpcsa.co.za/Conduct/Ethics

Hpcsa.co.za. (2018). Overview - HPCSA. Retrieved from http://www.hpcsa.co.za/Professionals

Hutchens, A. (1991). Indian herbalogy of North America. Boston: Shambhala.

Institute for Healthcare Improvement. (2019). Pareto Chart. Retrieved from http://www.ihi.org/resources/Pages/Tools/ParetoDiagram.aspx

Jahanbegloo, R., \& Parekh, B. (2011). Talking Politics. Oxford University Press.

Joubert, E., \& de Beer, D. (2011). Rooibos (Aspalathus linearis) beyond the farm gate: From herbal tea to potential phytopharmaceutical. South African Journal of Botany, 77(4), 869-886.

Jordaan, B. (2001). The protection of indigenous medical knowledge: a critical analysis. Retrieved from http://hdl.handle.net/20.500.11892/ 164365

Knapp, S., Gottlieb, M., Berman, J., \& Handelsman, M. (2007). When laws and ethics collide: What should psychologists do? Professional Psychology: Research and Practice, 38(1), 54-59.

Komakech, R., Kang, Y., Lee, J., \& Omujal, F. (2017). A Review of the Potential of Phytochemicals from Prunus africana (Hook f.) Kalkman Stem Bark for Chemoprevention and Chemotherapy of Prostate Cancer. 
Evidence-Based Complementary and Alternative Medicine (pp.1-10). https://doi.org/10.1155/2017/3014019

Kopnina, H., Washington, H., Taylor, B., \& Piccolo, J. (2018). Anthropocentrism: More than just a misunderstood problem. Journal of Agricultural and Environmental Ethics, 31(1), 109-127.

Korsgaard, C. (2004). Fellow creatures: Kantian ethics and our duties to animals. Tanner Lectures on Human Values, 24, 77-110.

Kozhikode, R., \& Li, J. (2012). Political pluralism, public policies, and organizational choices: Banking branch expansion in India, 1948-2003. Academy of Management Journal, 55(2), 339-359.

Kumar, V., \& Navaratnam, V. (2013). Neem (Azadirachta indica): Prehistory to contemporary medicinal uses to humankind. Asian Pacific Journal of Tropical Biomedicine, 3(7), 505-514.

Kurapati, K., Atluri, V., Samikkannu, T., Garcia, G., \& Nair, M. (2016). Natural products as anti-HIV agents and role in HIV-associated neurocognitive disorders (HAND): A brief overview. Frontiers in Microbiology, 6. https://doi.org/10.3389/fmicb.2015.01444

Laal, M. (2009). A brief history of enviroethics and its challenges. Journal of Medical Ethics and History of Medicine, 2(10), 1-5.

Laland, K., \& Hoppitt, W. (2003). Do animals have culture? Evolutionary Anthropology: Issues, News, and Reviews, 12(3), 150-159.

Le Blanc, J. (2009). Medical Autonomy and Vaccines: A Kantian Imperative Hektoen International. Retrieved from https://hekint.org/2017/01/30/ medical-autonomy-and-vaccines-a-kantian-imperative/

Luck, M., \& d'Inverno, M. (1995). A formal framework for agency and autonomy. In First International Conference on Multi-Agent Systems (pp. 254-260). Retrieved from https://nms.kcl.ac.uk/michael.luck/resources/ icmas95.pdf

Mack, P. (2004). Utilitarian ethics in healthcare. International Journal of The Computer, the Internet and Management, 12(3), 63-72. Retrieved from http://www.ijcim.th.org/past_editions/2004V12N3/ijcimv3n1_article6.pdf

Mandal, J., Ponnambath, D., \& Parija, S. (2016). Utilitarian and deontological ethics in medicine. Tropical Parasitology, 6(1), 5.

Masango, C. (2010). Indigenous traditional knowledge protection: Prospects in South Africa's intellectual property framework? South African Journal of Libraries and Information Science, 76(1), 74-80.

May, A. (2018). SA at the forefront of HIV/Aids research/Cape Argus. Retrieved from https://www.iol.co.za/capeargus/news/sa-at-the-forefront-of-hivaidsresearch-15117670

McClatchey, W., Mahady, G., Bennett, B., Shiels, L., \& Savo, V. (2009). Ethobotany as a pharmacological research tool and recent developments in CNS-active natural products from ethobotanical sources. Pharmacology \& Therapeutics, 123(2), 239-254. 


\section{Acta Educationis Generalis \\ volume 9, 2019, issue 2}

McIntosh, M. (2018). Looking at Culture: Symbolism, Adaptation, and Ideology. Retrieved from http://brewminate.com/looking-at-culture-symbolismadaptation-and-ideology/

Mondal, S., Bandyopadhyay, S. K., Ghosh, M., Mukhopadhyay, S., Roy, S., \& Mandal, C. (2012). Natural products: promising resources for cancer drug discovery. Anti-cancer Agents in Medicinal Chemistry, 12(1), 49-75.

Morrison, E., \& Furlong, E. (2009). Health Care Ethics: Critical Issues for the 21 st Century $\left(2^{\text {nd }}\right.$ ed., pp. 47-63). Jones \& Bartlett Learning.

Musgrave, M. (2016). African Customary Law in South Africa. Post-Apartheid and Living Law Perspectives by C. Himonga and T. Nhlapo (Eds.). 2015. Cape Town: Oxford University Press Southern Africa. International Journal of the Commons, 10(2),1205.

Nahra, C. (2014). The Harm Principle and the Greatest Happiness Principle: The Missing Link. Retrieved from http://www.scielo.br/scielo.php?script =sci_arttext\&pid=S0100-512X2014000100006

Naoum, V., Kyriopoulos, D., Charonis, A., Athanasakis, K., \& Kyriopoulos, J. (2016). The Pareto principle ("80-20 Rule") in healthcare services in Greece. Value in Health, 19(7), A618.

Narayanaswany, V. (1981). Origin and development of Ayurveda (A brief history). Ancient Science of Life, 1(1), 1-7.

Nortjé, N., \& Hoffmann, W. (2015). Ethics misconduct among dietetic practitioners in South Africa (2007-2013). South African Journal of Clinical Nutrition, 28(2), 77-80.

Open.edu. (2018). Study Session 1: Human Interactions with the Environment. Retrieved from http://www.open.edu/openlearncreate/mod/oucontent/ view.php?id=79926\&printable $=1$

Pharmacouncil.co.za. (2011). SAPC - South African Pharmacy Council. Retrieved from https://www.pharmcouncil.co.za/g_publicationsc.asp

Pouris, A., \& Inglesi-Lotz, R. (2014). The contribution of higher education institutions to the South African economy. South African Journal of Science, 110(3/4), 1-5.

Professional Board of Dietetics and Nutrition. (2006). Rules of Conduct Pertaining Specifically to the Profession of Dietetics. Pretoria, South Africa.

Ramdas, V. (2017). Ethics and Law in the Practice of Health Professions. Retrieved from http://www.gauteng.gov.za/campaigns/AntiCorruption Presentations/Viraj\%20Ramdas-\%20Ethics\%20and\%20Law\%20in\%20the $\% 20$ Practice $\% 20$ of $\% 20 \% 20$ Health $\% 20$ Professions $\% 20$ Gauteng $\% 20$ Nov $\%$ 202017.pdf

Recognition of Customary Marriages Act no. 120 OF 1998 (as amended). Retrieved from http://www.justice.gov.za/legislation/acts/1998-120.pdf

Rosenberg, G. (2001). A Pluralist Democracy. Retrieved from https://www.eurozine.com/a-pluralist-democracy/ 


\section{Acta Educationis Generalis \\ volume 9, 2019, issue 2}

Roy, E. (2018). New Zealand river granted same legal rights as human being. Retrieved from https://www.theguardian.com/world/2017/mar/16/newzealand-river-granted-same-legal-rights-as-human-being

Ryan, J. (2014). Towards an ethics of reciprocity: Ethnobotanical knowledge and medicinal plants as cancer therapies. Humanities, 3(4), 624-644.

Santini, A. (2018). The importance of referencing. The Journal of Critical Care Medicine, 4(1), 3-4.

Sciencedirect.com. (2010). Hoodia gordonii - an overview. Retrieved from https://www.sciencedirect.com/topics/agricultural-and-biological-sciences/ hoodia-gordonii

Sciencedirect.com. (2018). Rauvolfia serpentina - an overview. ScienceDirect Topics. Retrieved from https://www.sciencedirect.com/topics/medicineand-dentistry/rauvolfia-serpentina

Smith, P. (2014). How can universities contribute to social change? Retrieved from https://www.britishcouncil.org/voices-magazine/how-can-universities -contribute-social-change

South African Pharmacy Council (2008). Rules relating to the Code of Conduct. Pretoria: Government gazette, 1-15.

South African Rooibos Council (2017). South African Rooibos Council: Annual Report. Retrieved from https://sarooibos.co.za/wp/wp-content/uploads/ 2018/06/2017-SARC-Annual-Report_20180628.pdf

South African San Institute (2017). San Code of Research Ethics. Cape Town: South African San Institute. Retrieved from http://trust-project.eu/wpcontent/uploads/2017/03/San-Code-of-RESEARCH-Ethics-Booklet-final. pdf

Straus, J. (2017). Intellectual property rights and bioeconomy. Journal of Intellectual Property Law \& Practice, 12(7), 576-590.

Student.unsw.edu.au. (n.d.). Why is Referencing Important? Retrieved from https://student.unsw.edu.au/why-referencing-important

Tedlock, B. (2006). Indigenous heritage and biopiracy in the age of intellectual property rights. EXPLORE: The Journal of Science and Healing, 2(3), 256259.

Three Minute Philosophy: Immanuel Kant. (2009). Retrieved from https://www.youtube.com/watch? $\mathrm{v}=\mathrm{xwOCmJevigw}$

Time. (2016). Retrieved from http://time.com/4461874/change-the-worldcompanies-fortune/

Un.org. (2018). Climate Change. Retrieved from http://www.un.org/en/ sections/issues-depth/climate-change/

Valen, R., Fretheim, A., Kiserud, T., Bjertness, E., Grudt, S., \& Måseide, K. (2011). How Can Research Contribute to Better Global Health? Retrieved from https://tidsskriftet.no/en/2011/10/how-can-research-contribute-betterglobal-health 


\section{Acta Educationis Generalis \\ volume 9, 2019, issue 2}

van Wyk, B., \& van Staden, J. (2002). A review of ethnobotanical research in southern Africa. South African Journal of Botany, 68(1), 1-13.

van Wyk, B., de Wet, H., \& Van Heerden, F. (2008). An ethnobotanical survey of medicinal plants in the southeastern Karoo, South Africa. South African Journal of Botany, 74(4), 696-704.

Velamuri, S., \& Venkataraman, S. (2007). Why stakeholder and stockholder theories are not necessarily contradictory: A knightian insight. SSRN Electronic Journal.

Villavicencio Calzadilla, P. (2017). Climate justice: Case studies in global and regional governance challenges (Environmental Law Institute Washington DC 2016). Potchefstroom Electronic Law Journal/Potchefstroomse Elektroniese Regsblad, 20, 1.

Visser, J., \& Van Zyl IV, C. (2016). Legal ethics, rules of conduct, and the moral compass - considerations from a law student's perspective. Potchefstroom Electronic Law Journal/Potchefstroomse Elektroniese Regsblad, 19, 1.

Voigt, M., \& Hoogenboom, B. (2012). Publishing your work in a journal understanding: The peer review process. The International Journal of Sports Physical Therapy, 7(5), 452-460.

Whatmore, S. (2006). Materialist returns: practising cultural geography in and for a more-than-human world. Cultural geographies, 13(4), 600-609.

White, R. (1959). Motivation reconsidered: The concept of competence. Psychological Review, 66(5), 297-333.

Wipo.int. (2006). Resolving IP Disputes through Mediation and Arbitration. Retrieved from http://www.wipo.int/wipo_magazine/en/2006/02/article_ 0008.html

World Medical Association. (2019). World Medical Association: International Code of Medical Ethics. Retrieved from https://www.wma.net/policiespost/wma-international-code-of-medical-ethics/

Xavier, T., Kannan, M., Lija, L., Auxilla, A., Rose, A., \& Kumar, S. (2014). Ethnobotanical study of Kani tribes in Thoduhills of Kerala, South India. Journal of Ethnopharmacology, 152(1), 78-90.

Yumatle, C. (2016). Review of Jacob Levy's rationalism, pluralism, and freedom. SSRN Electronic Journal. 